\title{
Editorial
}

\section{Formación médica continuada y desarrollo profesional continuo. Una obligación compartida}

\author{
E. FERNÁNDEZ MONDEJAR ${ }^{\mathrm{a}}$ E I. ALÍA ${ }^{\mathrm{b}}$ \\ aUnidad de Cuidados Intensivos. Hospital de Traumatología. Hospital Universitario Virgen de las Nieves. Granada. España. \\ bUnidad de Cuidados Intensivos. Hospital de Getafe. Madrid. España.
}

\section{LA OBLIGACIÓN DEL APRENDIZAJE CONTINUO}

Los términos «formación médica continuada» $\mathrm{y}$ «desarrollo profesional continuo» son conceptos prácticamente intercambiables. Actualmente se prefiere el término de desarrollo profesional continuo porque con el mismo se pretende implicar de una forma más activa al médico y hacerle protagonista de su propia formación, identificando sus lagunas en cualquier ámbito profesional y diseñando un proceso formativo individualizado.

La práctica de la medicina nos obliga a un aprendizaje continuo para mantener al día nuestros conocimientos y habilidades. El objetivo no es otro que poder trasladar a la rutina asistencial aquellos avances científicos que puedan beneficiar a nuestros pacientes. Esta actualización permanente constituye una obligación ética que afecta a todos los médicos independientemente de la rama de la Medicina que ejerzan, pero en esta obligación no estamos solos. Los diferentes agentes que de una u otra forma actúan como «proveedores de salud», esto es: servicios de salud, hospitales, sociedades científicas, etc. comparten la responsabilidad de favorecer y desarrollar programas de formación que faciliten la competencia profesional de sus miembros. En este sentido, se trata de una obligación compartida en beneficio del paciente y tiene efectos en el desarrollo, calidad y cohesión del sistema sanitario (Ley de Ordenación de las Profesiones sanitarias. B.O.E. número 280, 22 de noviembre de 2003).

Cuando dos partes comparten la obligación por unos objetivos, es necesaria una tercera parte que de forma independiente arbitre o certifique el grado de cumplimiento de dichos objetivos. En este sentido, la formación o el grado de competencia profesional deberá ser acreditado por organismos independientes, de forma que solo las actividades acreditadas podrán ser tomadas en consideración.

El término «carrera profesional» tiene implicaciones prácticas más laborales pero también participa indirectamente en el concepto de desarrollo profesional continuo. La implantación de la carrera profesional en la mayor parte de nuestros sistemas sanitarios ha inyectado un vigoroso impulso a la necesidad que siente el profesional de certificar su competencia. A tal fin se pueden diseñar actividades (presenciales o no) dirigidas por diversas instituciones que tras someterse a un baremo establecido, son finalmente acreditadas oficialmente con un número de créditos en función de sus objetivos, duración, pertinencia, metodología, forma de evaluación, etc. Nuestra revista quiere contribuir en este campo ofreciendo la posibilidad de conseguir créditos de formación continuada que certifiquen unos determinados conocimientos.

\section{NUESTRA APORTACIÓN COMO REVISTA CIENTÍFICA}

En el panorama actual, con una masiva producción científica, se plantea el problema de cómo transferir los avances científicos a la práctica clínica. A veces hemos de admitir que pueden existir barreras estructurales que impiden o dificultan el avance del conocimiento o la implantación de una determinada técnica, pero lo más frecuente es que no se identifique ningún obstáculo y precisamente la sobreproducción científica a la que estamos sometidos no ayuda a la identificación de los avances trascendentales. 
En general, la simple lectura de un artículo puede no ser suficiente para inducir un cambio en la actitud terapéutica. Son necesarios esfuerzos educacionales que obliguen al lector a una participación activa y tomar partido por una u otra opción, lo que ayuda a fijar conceptos y a tomar decisiones prácticas. Hay que tener en cuenta que con los actuales medios diagnósticos, en particular a través de la imagen, el diagnóstico con frecuencia no constituye un reto en sí. El reto consiste en la toma de la decisión más apropiada. En este cometido, los sistemas educacionales interactivos facilitan la toma de decisiones. Este esfuerzo ha de verse recompensado además con la obtención de créditos útiles en la carrera profesional.
Con el presente número de Medicina Intensiva se inicia una etapa en la que se incluyen artículos seleccionados para formación médica continuada. Durante 2008 aparecerán 4 manuscritos en cada número y están acreditados con 12,2 créditos. Para acceder a ellos es necesario registrarse previamente en: www. formacion.elsevier.es/medicinaintensiva. El acceso a los mismos es absolutamente libre para los suscriptores de Medicina Intensiva y, tanto las respuestas a las preguntas como la obtención de créditos serán exclusivamente a través de la mencionada página web.

Espero que esta iniciativa tenga la doble utilidad que se persigue, contribuyendo a la mejora de la formación médica de nuestros lectores por una parte y, por otra, facilitando el desarrollo profesional continuo. 